\title{
Motor deficits and recovery during the first year following mild closed head injury
}

\author{
MARCUS H. HEITGER ${ }^{1,2}$, RICHARD D. JONES ${ }^{1,2,3}$, JOHN C. DALRYMPLE-ALFORD ${ }^{1,4}$, \\ CHRIS M. FRAMPTON ${ }^{1,2}$, MICHAEL W. ARDAGH ${ }^{1,5}$, \& TIM J. ANDERSON ${ }^{1,2,6}$ \\ ${ }^{1}$ Van der Veer Institute for Parkinson's \& Brain Research, Christchurch, New Zealand, ${ }^{2}$ Department of Medicine, \\ Christchurch School of Medicine E Health Sciences, Christchurch, New Zealand, ${ }^{3}$ Department of Medical Physics \\ and Bioengineering, Christchurch Hospital, Christchurch, New Zealand, ${ }^{4}$ Department of Psychology, University of \\ Canterbury, Christchurch, New Zealand, ${ }^{5}$ Emergency Department, and ${ }^{6}$ Department of Neurology, Christchurch \\ Hospital, Christchurch, New Zealand
}

(Received 8 August 2005; accepted 2 March 2006)

\begin{abstract}
Objective: This study examined motor impairments over 1 year following mild closed head injury (CHI). It is the first study to serially assess long-term oculomotor and upper-limb visuomotor function following mild head trauma.

Methods: Thirty-seven patients with mild CHI and 37 matched controls were compared at 1 week, 3 months and 6 months and 31 available pairs at 12 months post-injury on measures of saccades, oculomotor smooth pursuit, upper-limb visuomotor function and neuropsychological performance. Symptomatic recovery was sampled using the Rivermead Postconcussion Symptoms Questionnaire.

Results: At 1 week, the group with CHI reported high levels of post-concussional symptoms and exhibited prolonged saccade latencies, increased directional errors, decreased saccade accuracy and impaired fast sinusoidal smooth pursuit concomitant with increased arm movement reaction time, decreased arm movement speed and decreased motor accuracy on upper-limb visuomotor tracking tasks. Neuropsychological testing identified deficits only in verbal learning and speed of processing while attention, short-term/working memory and general cognitive performance were preserved. At 3 and 6 months, the group with CHI continued to show deficits on several oculomotor and upper-limb visuomotor measures in combination with some deficits on verbal learning and improved, yet abnormal, levels of post-concussional symptoms. At 12 months, the group with CHI had no cognitive impairment but residual deficits in eye and arm motor function and continued to show elevated levels of post-concussional symptoms.

Conclusions: The findings indicate that multiple motor systems are measurably impaired up to 12 months following mild $\mathrm{CHI}$ and that instrumented motor assessment may provide sensitive and objective markers of cerebral dysfunction during recovery from mild head trauma independent of neuropsychological assessment and patient self-report.
\end{abstract}

Keywords: Closed head injury, recovery, saccades, oculomotor smooth pursuit, upper-limb

\section{Introduction}

Mild closed head injury (CHI) is a substantial cause of morbidity world-wide. Approximately $80 \%$ of head injury admissions are categorized as mild with 100 to 300 cases per year per 100000 population $[1,2]$. It follows that mild CHI is one of the commonest causes of emergency department visits and hospital admissions [3] and the source of substantial related costs for health care providers [4-6].

There is increasing evidence that even mild head trauma is associated with a physical impact on the brain that can result in neuronal injury and subsequent cerebral dysfunction [7-11]. This physical

Correspondence: Marcus Heitger, Van der Veer Institute for Parkinson's \& Brain Research, 16 St Asaph Street, Christchurch, New Zealand. Tel: +6433786074. Fax: +6433786080. E-mail: marcus.heitger@chmeds.ac.nz 
impact is thought to contribute to post-concussional symptoms of both a physical and cognitive nature $[9,12-14]$. Within the first $6-12$ months following mild CHI, an estimated $30-40 \%$ of patients are likely to show ongoing health problems [15-20].

Despite this potentially debilitating impact of mild CHI and the subsequent demand for objective tools to confirm injury status and track functional recovery, there are currently no assessment options that are equally accurate and cost-efficient in objectively quantifying the long-term presence of residual brain dysfunction after mild CHI. Imaging is expensive and does not provide a detailed picture of functional aspects of the injured brain [9, 21-23]. The application of neuropsychological testing to confirm injury status and track recovery in patients with mild CHI has been hampered by its susceptibility to pre-morbid factors such as age, IQ and socioeconomic status [24-26]. External factors are likely to outweigh the head-trauma-effect on neuropsychological tests and the likelihood that abnormal neuropsychological performance indicates the presence of a pathological condition has been estimated to be under $50 \%$ in cases with mild head trauma [27]. Similarly, the use of biochemical markers to quantify the impact of mild $\mathrm{CHI}$ on the brain has been unsatisfactory [28-30].

Based on earlier findings of oculomotor and upper-limb visuomotor impairment at 1 week after mild CHI [31-33], it was considered that there may be measurable long-term abnormalities in eye and arm motor function after mild CHI and that motor testing may be a useful supplementary tool in objectively quantifying residual brain dysfunction during recovery from mild head trauma. The approach of examining motor performance as an independent functional biomarker for the adverse impact of mild CHI takes advantage of the established knowledge on motor control, its complex functional neuroanatomy and the availability of established tools and paradigms to assess motor function [34-40]. Whilst it was the principal aim of this study to establish whether there are long-term motor impairments within the first year following mild CHI, the authors also wanted to determine if the recovery of these deficits parallels overall patient recovery.

Saccadic deficits have been described after severe head trauma [41] and several studies have examined upper-limb motor deficits and recovery of arm/hand motor function after moderate-to-severe head trauma using tasks such as finger tapping [42-45], visuomotor tracking tasks [46, 47], video games [48], reaching [49, 50] and grasping and reaction time tests [50]. However, this study is the first to serially assess long-term deficits in saccades and oculomotor smooth pursuit following head injury and to measure long-term upper-limb visuomotor function specifically after mild head trauma. It is also unique in taking a multi-modality approach of gauging ongoing cerebral dysfunction after mild $\mathrm{CHI}$ by tracking the recovery of motor performance, neuropsychological function and self-reported symptom status in a homogeneously mild CHI patient group.

\section{Participants and methods}

\section{Participants}

Thirty-seven subjects (13 female and 24 male) with mild CHI (Glasgow Coma Scale [GCS] score 13: four cases, 14: 12 cases, 15: 21 cases) were recruited from patients presenting with acute head injury to Christchurch Hospital (the principal hospital for a regional population of over 400000 ). The GCS used was the score on first assessment (i.e. the first recorded GCS post-injury). In most cases, this was at time of admission to the Emergency Department. In some cases, the GCS was first assessed by the ambulance team prior to arrival at the hospital. Patients had to have a score on GCS of between 13-15 on first assessment, without falling below 13 at any consecutive assessment at the hospital. At the time of recruitment, no standardized method was in practice to assess duration of posttraumatic amnesia (PTA) in patients presenting with mild head injury to the Emergency Department at Christchurch Hospital and PTA duration was not routinely noted in patient files (apart from brief comments on the lack of recall of the injury-event if applicable). Hence, an iterative process was used to (a) confirm that PTA was less than 24 hours (the only required screening criterion) and (b) provide an approximation of length of PTA (the GCS score was the principal factor for CHI classification). At the initial pre-recruitment interview at the hospital patients were asked about their first memory following the injury. If the remembered event fell within a 24 hour period, it was assessed whether the patient remembered being at the scene after the accident/regaining consciousness, being helped by others (e.g. extraction from a vehicle, somebody clearing their bike off the street or calling an ambulance), the arrival of the ambulance (if applicable, standard response time of ambulances within city boarders taken as time approximation), being in the ambulance, arriving at the hospital (time was recorded on admission sheet as was time of accident in the case of MVAs and most sport accidents), treatment events for which the time 
was noted on the patient chart, being served a meal (usually dinner or breakfast for patients who stayed overnight).

All patients had experienced PTA ranging between $\sim 2$ minutes and 22 hours (mean $=2$ hours 40 minutes) and 32 patients had a confirmed loss of consciousness (mean $=3.96$ minutes, range $0.5-15$ minutes). Mean age was 29.1 years (SD 12.7, range 15-56 years) and mean years of education was 13.6 (SD 2.56, range 8-19 years). All patients were either employed or attended institutions for secondary or tertiary education and none was involved in litigation. Other potential participants were excluded if there was evidence of any influence of alcohol or psychoactive drugs at time of injury, regular intake of psychoactive drugs or history of drug abuse, central neurological disorder or psychiatric condition, structural brain damage or haematoma on CT head scan (where obtained), oculomotor or somatomotor deficits upon clinical examination, presence of strabismus, visual acuity of worse than $6 / 12$, skull fractures or prior history of mild, moderate or severe head injury with persisting symptoms or complaints.

The control group consisted of subjects with no history of mild, moderate or severe head injury with persisting symptoms or complaints, no central neurological disorder or psychiatric condition and no regular intake of psychoactive drugs or history of drug abuse. The controls were individually matched to each CHI case with respect to age (within 3 years for patients $>18$ years, within 1 year for patients $<18$ years), gender and years of formal education (within 2 years for patients $>18$, within 1 year for subjects $<18)$. The mean age for the control group was 29.2 years (SD 12.6, range 15-57 years) and mean years of formal education was 13.7 (SD 2.71, range 9-19 years). The head injured group and the controls had equivalent IQ (mean IQ CHI group at 1 week: $110.8 \pm 11.6$ vs. controls: $112.4 \pm 10.5$ ). Controls were recruited via a volunteer database made available by the Department of Psychology at the University of Canterbury, Christchurch, New Zealand. These volunteers are interested in taking part in research studies and have agreed to be contacted for this purpose. In cases where a subject with head injury could not be matched with a control from the database, controls were recruited amongst siblings, relatives or friends of the head injured participant (patients were happy to suggest and contact potential controls having been explained the necessity for having a control and the matching criteria).

Throughout the study, none of the participants was hospitalized or developed secondary health problems related to other causes which could have affected any of the measures. Subjects were offered compensation for travel costs to attend the testing at the hospital but received no other payment. The project was approved by the Canterbury Ethics Committee and written consent was obtained from all participants.

\section{Oculomotor assessment}

The assessment methods, paradigm parameters and key measures of motor performance were identical to an earlier study and have been described in detail elsewhere $[31,32]$. This study incorporated paradigms for reflexive saccades ('looking at the stimulus', 44 saccades, stimuli jumping randomly by $5,10,15,20,25$ or $30^{\circ}$ in a horizontal direction, at intervals varying pseudorandomly between 1.0-1.6 seconds), anti-saccades ('looking away from the stimulus to its mirror-location on the opposite side of the screen', 32 anti-saccades, stimuli at 5 and $15^{\circ}$ off centre, at intervals varying pseudorandomly between 1.0-1.6 seconds, balanced for left and right), memory-guided sequences of saccades ('performing a memorized sequence of saccades', six different sequences, each with four steps, duration of 1.0 second per step, each sequence practised five times, then performed once, followed by presentation of the next sequence), self-paced saccades ('do-as-manyas-possible'-self-pacing for 30 seconds between two stationary targets, $\pm 15^{\circ}$ off centre) as well as sine and random oculomotor smooth pursuit ('tracking a continuously moving target', sine at 40 and $60^{\circ} \mathrm{s}^{-1}$ peak velocity and random smooth pursuit, mean peak velocity $80^{\circ} \mathrm{s}^{-1}$, each task 40 second duration). The only change from an earlier study was the presentation of the anti-saccade paradigm by way of video screen using different colours for fixation (red) and anti-saccade stimuli (green), rather than by red LED (light-emitting diode) bar.

Eye movements were recorded using an IRIS infrared limbus tracker (Skalar Medical, BV, Delft, The Netherlands) [51]. Eye position signals were low-pass filtered at $100 \mathrm{~Hz}$, sampled and digitized at $200 \mathrm{~Hz}$ and recorded for off-line analysis. Subjects were seated in a darkened room. Head movements were stabilized via a wax bite-bar. Eye movements were elicited by instructing the subject to follow a computer-generated stimulus (for reflexive and anti-saccades: a red/green square target, subtending $0.75^{\circ}$, front-projected onto a video screen $1.72 \mathrm{~m}$ in front of the subject; for memory-guided sequences and self-paced saccades: a LED bar $1.5 \mathrm{~m}$ in front of the subject; for 
oculomotor smooth pursuit: a circle with a centred cross, subtending $4.82^{\circ}$, front-projected onto a video screen $1.72 \mathrm{~m}$ in front of the subject). The tests were generated and controlled by a PC which also recorded the data for off-line analysis [52]. The equipment was calibrated at the start of the session and between tests.

Mean values of the key measures over all trials in a particular test paradigm were used in analyses. Before the test proper, subjects were shown an example of each paradigm in order to familiarize them with the task requirements. Key measures (per paradigm) were saccade latency (ms) (reflexive, antiand self-paced saccades), saccade velocity $\left({ }^{\circ} \mathrm{s}^{-1}\right)$ (reflexive, anti- and self-paced saccades), number of self-paced saccades within $30 \mathrm{~s}$, directional errors (anti-saccades, memory-guided sequences), mean absolute position error of the final eye position and gain (eye position/stimulus position) of the primary saccade and final eye position [32]. An 'absolute time index' (ATI = subject's total response time/ duration of the sequence) and 'inter-response-index' (IRI, measure for the subject's ability to maintain a constant rhythm during a sequence, centred around the optimum of zero) [31] was calculated for memory-guided sequences. Key measures for oculomotor smooth pursuit were the average eye peak velocity $\left({ }^{\circ} S^{-1}\right)$ after removal of all saccades from the tracking performance and the tracking lag (ms).

\section{Upper-limb visuomotor testing}

The test set-up and paradigm parameters were identical to a previous study [32], comprising tests of visual acuity, visual perception and resolution, basic arm motor function (movement speed and steadiness) and several one-dimensional (1-D) visuomotor tracking tasks (sine and random preview/non-preview and step tracking) [32, 35]. Subjects were seated in front of a colour monitor $(312 \times 234 \mathrm{~mm})$ with an eye-to-screen distance of $132 \mathrm{~cm}$. The 1-D tracking tasks used a steering wheel (395 mm diameter) as subjects' output sensor, which moved a vertical white arrow $(16 \mathrm{~mm}$ high, $11 \mathrm{~mm}$ wide) horizontally on a black background (top of arrow $58 \mathrm{~mm}$ from bottom of the screen). Subjects placed their preferred hand at a fixed position on the steering wheel (10 o'clock mark for left handers and 2 o'clock mark for right-handers or, for tests of arm speed, reaction time and steadiness, the hand was placed at the 12 o'clock mark). Key measures for all 1-D tracking tasks were the mean absolute error $(\mathrm{mm}$; horizontal distance between arrow head and target) and tracking lag (ms) [32].

\section{Neuropsychological tests}

Attention, working memory, episodic memory and speed of information processing was assessed using the Paced Auditory Serial Addition Task (PASAT) [53], the California Verbal Learning Test I (CVLT) [54], Symbol Digit Modalities Test (SDMT) [55] and the Trail Making Test A+B (TMT A + B) [56]. General cognitive performance was evaluated with the Vocabulary Test and Matrix Reasoning sub-tests of the Wechsler Abbreviated Scale of Intelligence (WASI) [57]. Standardized instructions were followed for all tests.

\section{Symptom evaluation: Rivermead Post-concussion Symptoms Questionnaire}

The presence of post-concussional symptoms and complaints was assessed using the Rivermead Postconcussion Symptoms Questionnaire (RPSQ) [58]. This questionnaire was developed and standardized by the Oxford Head Injury Service (Oxford, UK) and is a widely used tool to assess and quantify the presence of post-concussional complaints in head trauma patients, rating 16 symptoms on a scale from 0 (i.e. not experienced at all) to 4 (i.e. a severe problem). The key measure was the cumulative total of all symptoms.

\section{General procedures}

Patients were assessed within 1 week of injury (mean $5.5 \pm 3.0$ days) and then at 3 months (90 \pm 5.5 days), 6 months (182 \pm 15 days) and 12 months (365 \pm 14 days). Controls completed the same number of assessments at the same time intervals. Patients completed the RPSQ in each session while controls completed it once to establish a control base-line.

\section{Statistical analysis}

Most measures were not normally distributed and, therefore, non-parametric Wilcoxon MatchedPairs statistics were used to compare patients and controls at 1 week and at 3, 6 and 12 months post-injury. The analysis at 12 months included only 31 matched pairs, due to six patients not returning for their 1-year follow-up. Differences between groups were considered significant at a two-tailed $p$ value $\leq 0.05$. No formal adjustment was made to preserve the Type I error rate as this study was primarily viewed as a screening study identifying putative deficit measures which may be further examined for clinical use. Based on a previous work in the area of eye and arm motor function after mild CHI [31, 32], 37 subject pairs were considered sufficient to provide adequate power $(>80 \%)$ to ensure detection of group differences on measures of clinical relevance 
(an effect size of 0.5 or more at a two-tailed $\alpha=0.05)$.

\section{Results}

Eye movement performance

Saccades-reaction times. The group with CHI had deficits on saccadic reaction times at 1 week, but not at 3, 6 or 12 months post-injury. At 1 week, the group with CHI demonstrated prolonged anti-saccade latencies (Figure 1(a)) and a trend towards prolonged correction times for erroneous prosaccades in the anti-saccade task (CHI mean \pm SD: $129 \pm 54$ vs. control mean $\pm \mathrm{SD}$ : $109 \pm 54 \mathrm{~ms}, p=0.066)$.
No deficits were detected for simple reflexive latency, latency of directional errors (erroneous prosaccades) in the anti-saccade task or the inter-saccadic latency of self-paced saccades. No statistically significant group differences were detected on any saccadic latency measure at 3,6 or 12 months post-injury.

Saccades-velocity. The group with CHI exhibited normal saccadic velocities on all tasks throughout the year (data not shown).

Saccades-directional errors. The group with CHI made considerable directional errors in memoryguided sequences but not the anti-saccade task.
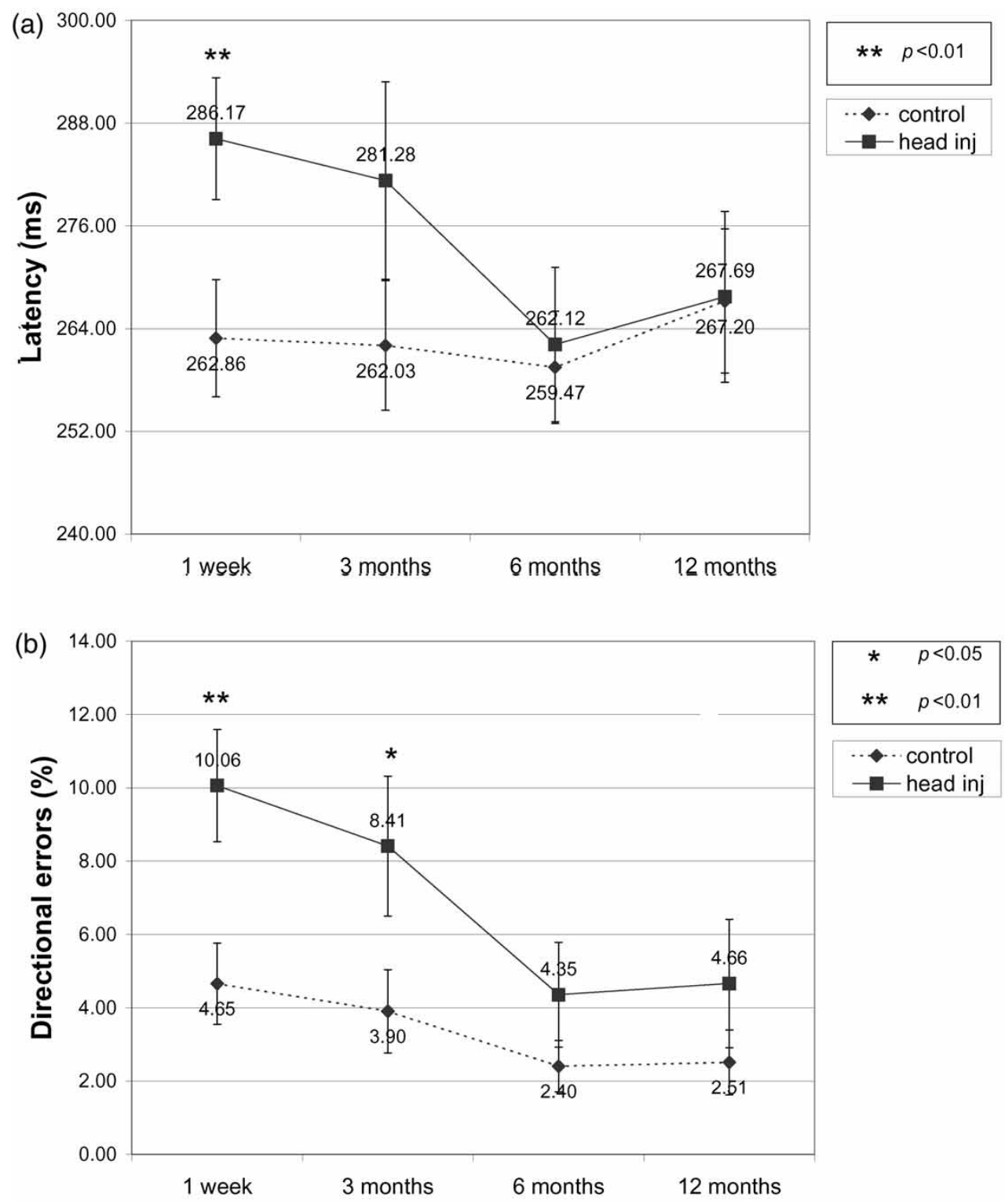

Figure 1. Oculomotor deficits during the first year post-injury: anti-saccade latency (a) and directional errors on sequences of memory-guided saccades (b). Error bars show standard errors. 
At 1 week, the participants with head injury had more directional errors in their performance of memory-guided sequences of saccades (Figure $1(b))$. There were no differences in the number of directional errors (erroneous prosaccades) during the anti-saccade task $(24.7 \pm 20.5$ vs. $19.3 \pm 13.6 \%$, $p=0.414)$. At 3 months, the group with CHI continued to show an increased number of directional errors on sequences of memory-guided saccades (Figure 1(b)), whereas rates of erroneous prosaccades in the anti-saccade task were the same in both groups $(18.2 \pm 18.1$ vs. $15.1 \pm 11.5 \%$, $p=0.825)$. At 6 and 12 months, there were no abnormalities in directional saccade errors.

Saccades-motor accuracy. The participants with head injury exhibited persistent saccadic inaccuracy on memory-guided sequences and anti-saccades for several months post-injury. At 1 week, the group with CHI showed markedly poorer spatial accuracy on the mean absolute position error of final eye position in antisaccades (Figure 2(a)) and sequences of memory-guided saccades (Figure 2(b)). The patients demonstrated normal spatial accuracy on reflexive saccades, although there was a trend towards very slight hypometria, both for primary $\left(G_{p} 0.96 \pm 0.05\right.$ vs. $\left.0.98 \pm 0.04, p=0.056\right)$ and final reflexive saccade gain $\left(\mathrm{G}_{f} 1.0 \pm 0.02\right.$ vs. $1.01 \pm 0.02, p=0.078)$. Accuracy of self-paced saccades was normal throughout the year.

At 3 months the group with CHI continued to exhibit an increased absolute position error in anti-saccades (Figure 2(a)) and sequences of memory-guided saccades (Figure 2(b)). The slight hypometria on reflexive saccades observed at 1 week remained at 3 months, showing a minor group (a)

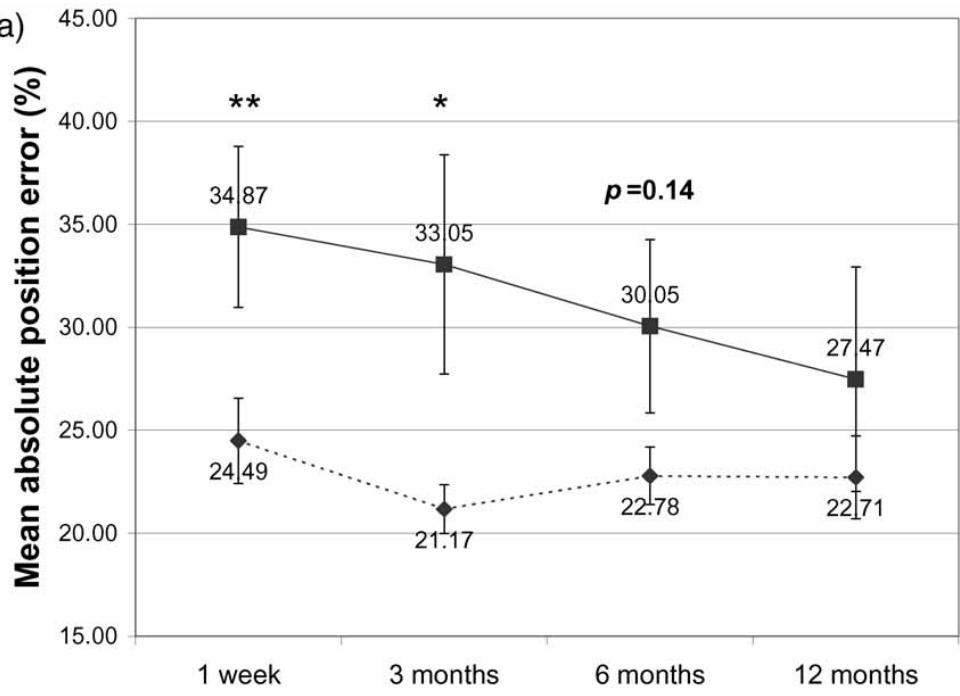

(b)

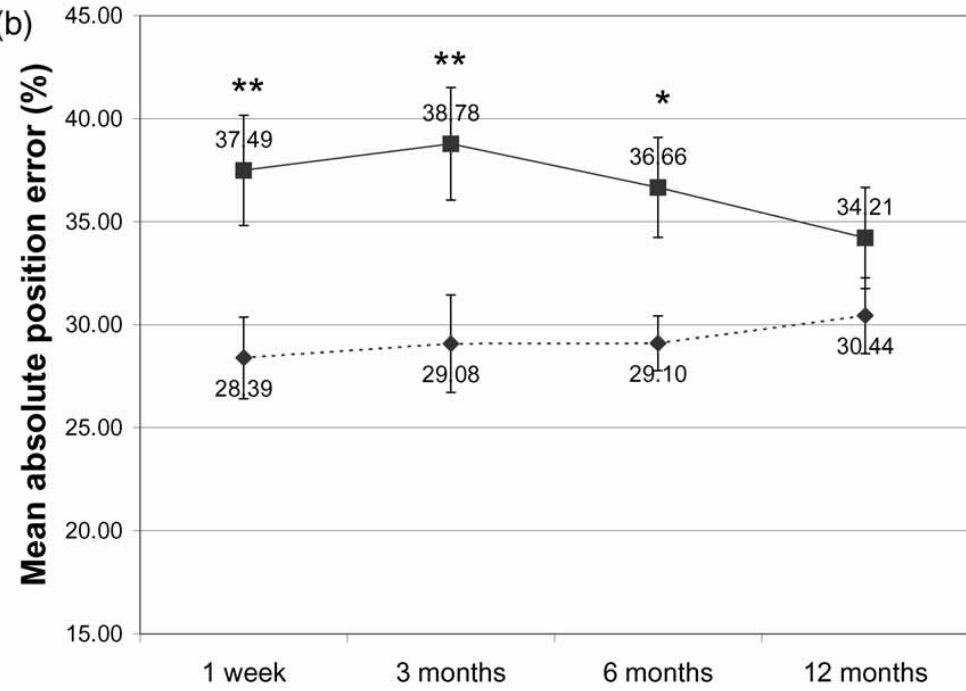

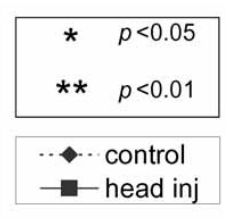

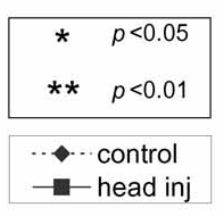

Figure 2. Oculomotor deficits during the first year post-injury: mean absolute position errors of anti-saccades (a) and sequences of memory-guided saccades (b). Error bars show standard errors. 
difference on primary $\left(\begin{array}{lll}G_{p} & 0.95 \pm 0.04 & \text { vs. }\end{array}\right.$ $0.98 \pm 0.04, p=0.034)$ and final reflexive saccade gain ( $G_{f} 0.99 \pm 0.02$ vs. $\left.1.01 \pm 0.01, p=0.004\right)$. At 6 months, a clear deficit remained on the absolute position error in sequences of memory-guided saccades (Figure 2(b)), but by 12 months, no deficits in saccadic accuracy were observed on any task.

Saccades-timing and rhythm of memory-guided sequences. Timing of saccades (absolute time index) was normal at 1 week $(1.02 \pm 0.14$ vs. $0.99 \pm 0.12, p=0.4)$ and remained normal throughout the year. Similarly, the ability to keep a steady rhythm within sequences was not impaired $(0.09 \pm 0.04$ vs. $0.08 \pm 0.03, p=0.3)$ and remained unimpaired.
Oculomotor smooth pursuit. At 1 week, the group with CHI had a slowed average peak tracking velocity on fast sinusoidal smooth pursuit $\left(60^{\circ} \mathrm{s}^{-1}\right)$ (Figure 3(a)) in conjunction with an abnormal pursuit tracking lag on the same task (Figure 3(b)). There were no group differences in average peak velocity or lag with the slower (i.e. $40^{\circ} \mathrm{s}^{-1}$ ) sinusoidal and (fast) random smooth pursuit tasks but there was a trend towards a prolonged random tracking lag in the patient group $(44.05 \pm 14.8$ vs. $37.78 \pm$ $15.2 \mathrm{~ms}, p=0.086)$. Performance on these two tasks remained normal at 3, 6 and 12 months.

By 6 months, the patients continued to have slowed average peak velocity on $60^{\circ} \mathrm{s}^{-1}$ sinusoidal pursuit (Figure 3(a)) and a marginally slowed average peak velocity and abnormal lag on this task at 12 months post-injury (Figure 3(b)).
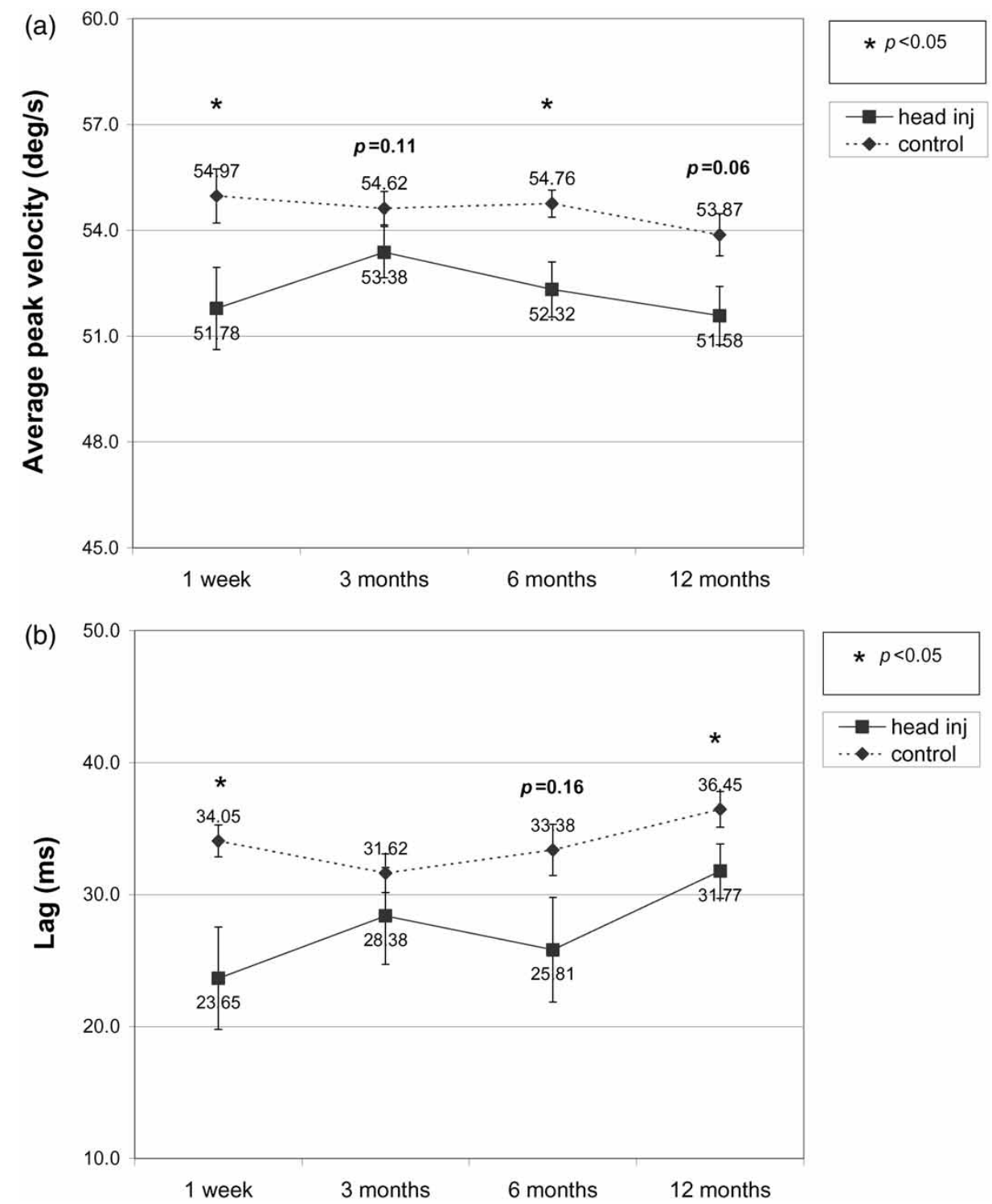

Figure 3. Oculomotor deficits during the first year post-injury: average peak velocity and lag of fast sinusoidal oculomotor smooth pursuit (a and b, respectively). Error bars show standard errors. 


\section{Upper-limb visuomotor performance}

The group with $\mathrm{CHI}$ had long-term impairments in upper-limb visuomotor function, including poorer upper-limb movement accuracy and slowed ballistic arm movement velocity up to 12 months post-injury.

At 1 week, no deficits were found on visual acuity, visual resolution, static visual perception, dynamic visual perception or arm movement steadiness and these measures remained normal throughout the year.

Conversely, the group with $\mathrm{CHI}$ had prolonged arm movement reaction time (Figure $4(a)$ ) and markedly reduced (ballistic) arm movement peak velocity (Figure $4(\mathrm{~b})$ ). The patient group showed increased mean absolute errors on all non-preview 1-D tracking tasks, these being sine tracking
(Figure 5(a)), random tracking (Figure 5(b)) and step tracking (Figure 5(c)), with a trend towards increased mean absolute error on random-preview tracking $(5.33 \pm 1.6$ vs. $4.71 \pm 1.4 \mathrm{~mm}, p=0.059)$. Similarly, at 1 week, the patients had prolonged lag on sine tracking (Figure 6(a)), random tracking (Figure 6(b)), random-preview tracking $(81.0 \pm 63.8$ vs. $53.8 \pm 64 \mathrm{~ms}, p=0.035)$ and step tracking (Figure 6(c)). No deficits were found on sinepreview tracking and performance on this task remained normal at 3, 6 and 12 months.

At 3 months, arm movement reaction time of the group with CHI had improved to normal (Figure 4(a)), while arm movement velocity remained impaired (Figure 4(b)). Similarly, mean absolute errors remained impaired on sine tracking
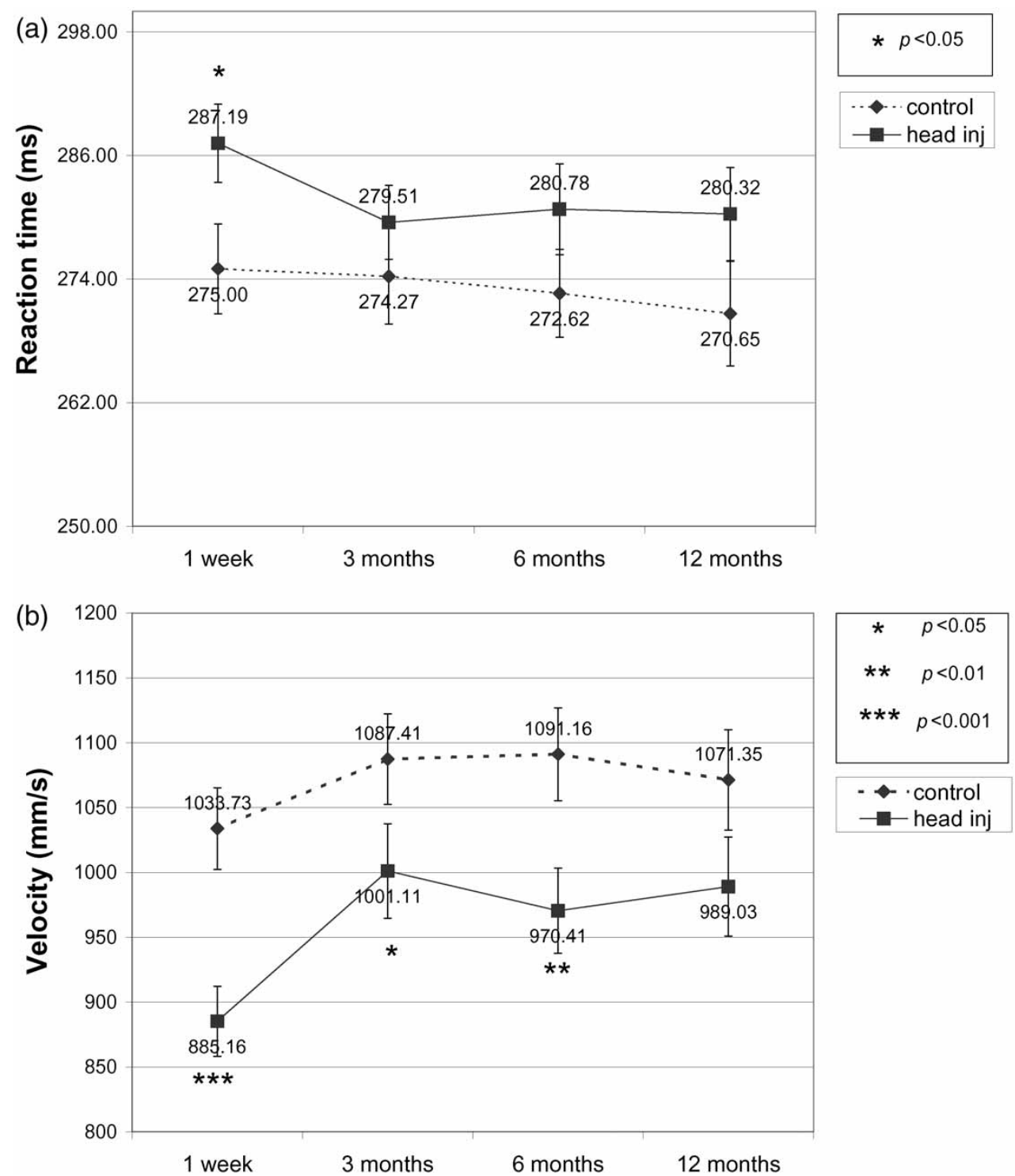

Figure 4. Upper-limb motor measures during the first year post-injury: arm movement reaction time (a) and upper-limb movement peak velocity (b). Error bars show standard errors. 

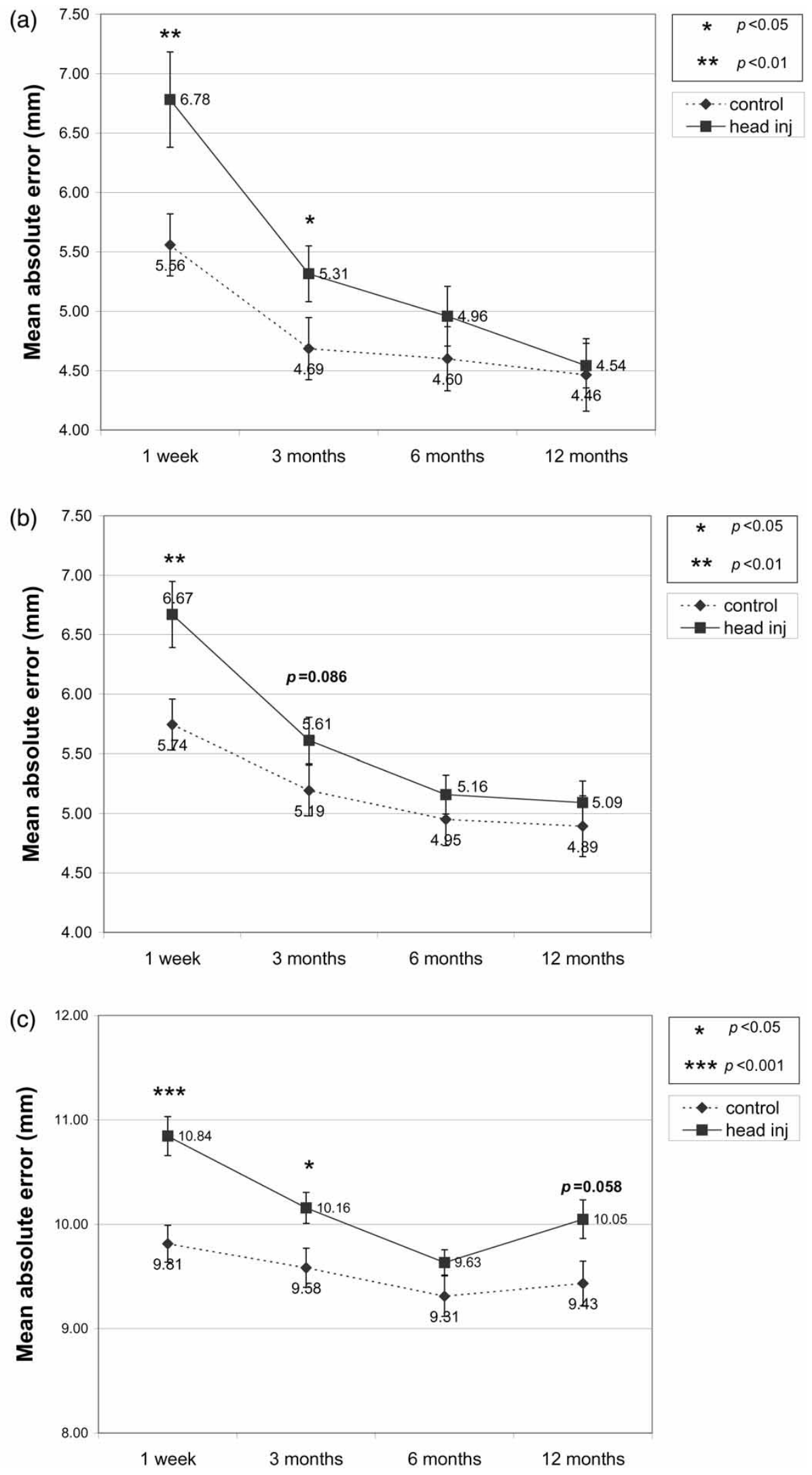

Figure 5. Upper-limb motor measures during the first year post-injury: mean absolute errors on sine (a), random (b) and step tracking (c). Error bars show standard errors. 
(Figure 5(a)) and step tracking (Figure 5(c)). In addition, there was a trend towards a higher mean absolute error on random tracking in the patient group (Figure 5(b)). The patient group also exhibited prolonged tracking lags on sine tracking (Figure 6(a)), random tracking (Figure 6(b)) and step tracking (Figure 6(c)).

At 6 months, the group with $\mathrm{CHI}$ continued to have slowed arm movement velocity (Figure 2(b)) and prolonged tracking lag on sine tracking (Figure 6(a)) and step tracking (Figure 6(c)). The deficits on all other measures of upper-limb motor accuracy had improved to non-significant levels.

At 12 months, no difference was detected on arm movement peak velocity $(p=0.094)$ (Figure $4(\mathrm{~b})$ ) and the deficits on the visuomotor tracking tasks had resolved except for step tracking in which lag was impaired (Figure 6(c)) and mean absolute error marginally impaired (Figure 5(c)).

\section{Neuropsychological testing}

No deficits were found on the PASAT (2.4, 2.0, 1.6 and $1.2 \mathrm{~s}$ pacing), TMT A/B time-to-completion or errors and the WASI (including Vocabulary and Matrix Reasoning $T$-scores) throughout the first year post-injury. At 1 week, the group with $\mathrm{CHI}$ showed deficits only on the SDMT ( $z$-score $-0.07 \pm 0.93$ vs. $0.56 \pm 1.04, p=0.007$ ) and CVLT (Figures 7 and 8). The impairments of the patient group on the CVLT comprised lower scores on the total standard score (Figure 7(a)), short delay free recall (Figure 7(b)), short delay cued (Figure 7(c)), long delay free recall (Figure 8(a)), long delay cued recall (Figure 8(b)) and List A/trial 5 (Figure 8(c)). The patients did not differ on serial or semantic cluster scores, meaning that the controls were not better naming the shopping items in correct order and both groups had the same tendency to group the items into their categories (i.e. fruit, tools, spices, etc.) when naming them. The group with $\mathrm{CHI}$ showed preserved item recognition (recognition hits) but showed some difficulty in the differentiation between true items and non-items during longdelay recognition (recognition discriminability, $-0.38 \pm 0.72$ vs. $-0.11 \pm 0.52, p=0.053)$.

At 3 months, the patient group showed deficits only on the CVLT, comprising lower scores on total standard score (Figure 7(a)), short delay free and cued recall (Figures $7(\mathrm{~b})$ and (c)), as well as long delay free and cued recall (Figures $8(\mathrm{a})$ and (b)). At 6 months, deficits remained only on CVLT total standard score (Figure 7(a)), short delay cued recall (Figure 7(c)) and long delay free recall (Figure 8(a)), while short delay free recall and long delay cued recall showed only marginal differences (Figures $7(\mathrm{~b})$ and $8(\mathrm{~b})$ ). At this point, deficits on
List A/trial 5 resurfaced (Figure 8(c)), although this measure had been normal at 3 months. The group with CHI also showed a lower score on recognition discriminability $(-0.11 \pm 0.46$ vs. $0.11 \pm 0.31$, $p=0.017)$ indicating that the patients still experienced problems in differentiating between true items and non-items during long-delay recognition, although item recognition (recognition hits) was preserved (as observed at 1 week and 3 months). At 12 months, no cognitive deficits remained, with the exception of a marginal group difference on the CVLT total standard score (Figure 7(a)).

\section{Health assessment measures}

At 1 week, the patient group had comparatively high scores on the cumulative total of the Rivermead Post-concussion Symptoms Questionnaire (RPSQ) $(19.81 \pm 11.72 \quad$ vs. $4.08 \pm 5.42, \quad p<0.001)$ (Figure 4). Over $91 \%$ of patients reported an injury-related increase in levels of RPSQ-symptoms (i.e. with a score of 2 or higher it was considered at least a mild problem by the reporting patient) and no patient was entirely symptom-free (Table I).

At 3 months, the RPSQ total score had improved but remained abnormally high $(9.81 \pm 9.89$ vs. $4.08 \pm 5.42, p<0.001$ ) (Figure 9). Similarly, the $\mathrm{CHI}$ group had improved, yet abnormal rates of postconcussional complaints, with $59.5 \%$ of patients reporting symptoms with a score of 2 or higher (i.e. an injury-related increase in symptom levels) (Table I). Only $16.2 \%$ were entirely symptom-free.

At 6 months, the average level of postconcussional symptoms was still higher in the group with CHI compared to the control baseline level (RPSQ total $10.24 \pm 10.65$ vs. $4.08 \pm 5.02$, $p<0.001$ ) (Figure 9). Over $51 \%$ of patients continued to report post-concussional symptoms with a score of 2 or higher, whilst only $13.5 \%$ of patients were entirely symptom-free (Table I).

At 12 months, the RPSQ total of the patient group remained at an increased level similar to 6 months $(10.13 \pm 11.96$ vs. $4.39 \pm 5.74, p=0.020)$ (Figure 9) and more than $50 \%$ of the remaining 31 patients continued to report scores of 2 or higher on at least one post-concussional symptom on the RPSQ, with only $38.7 \%$ being entirely symptom-free at 1 year post-injury (Table I).

\section{Discussion}

The principal and novel finding of this study, the first to serially examine oculomotor and upper-limb visuomotor function after mild $\mathrm{CHI}$, is evidence of previously unreported persistent eye and arm motor deficits during the first 12 months after mild head trauma. The group with $\mathrm{CHI}$ had prolonged 

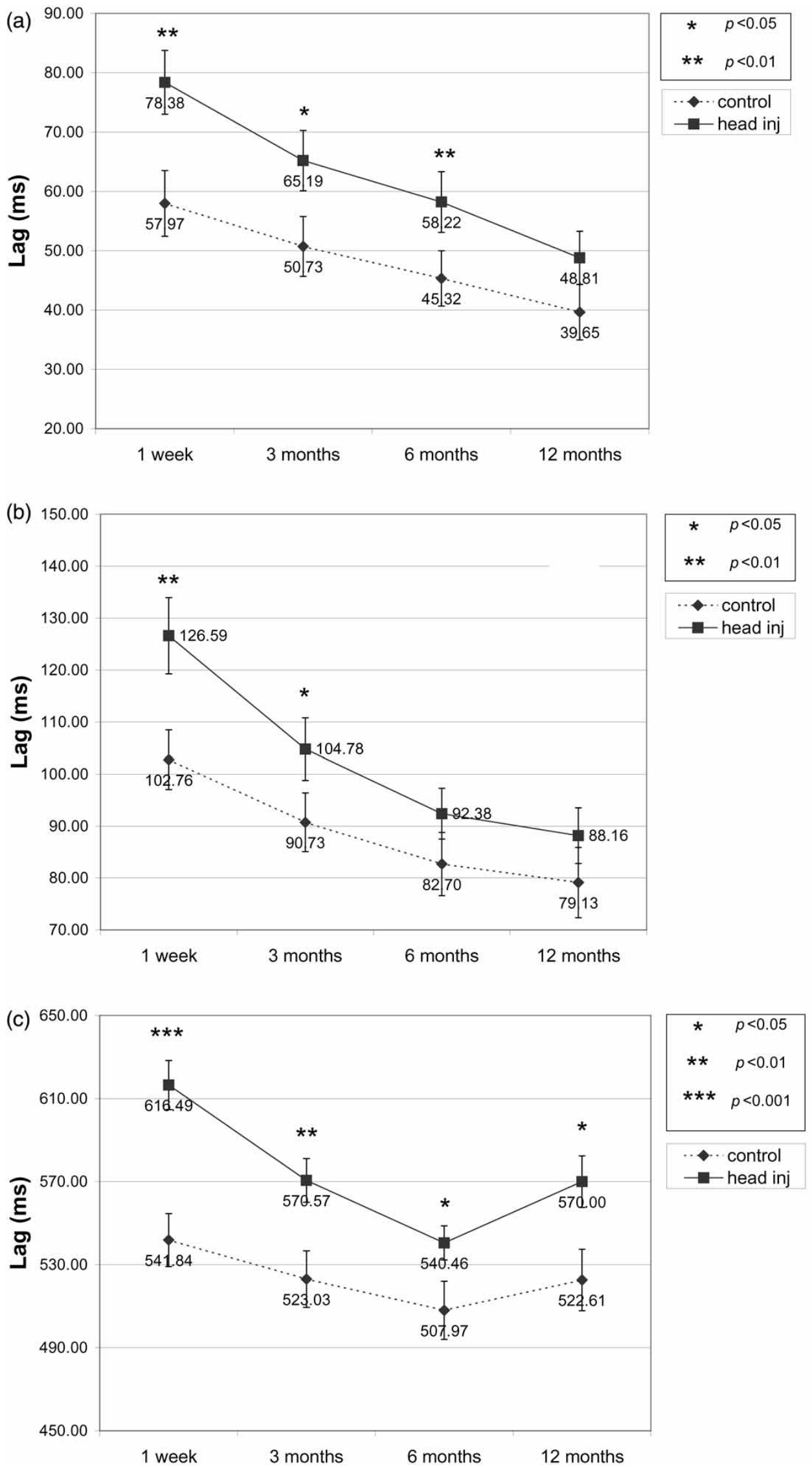

Figure 6. Upper-limb motor measures during the first year post-injury: Lag on sine (a), random (b) and step tracking (c). Error bars show standard errors. 

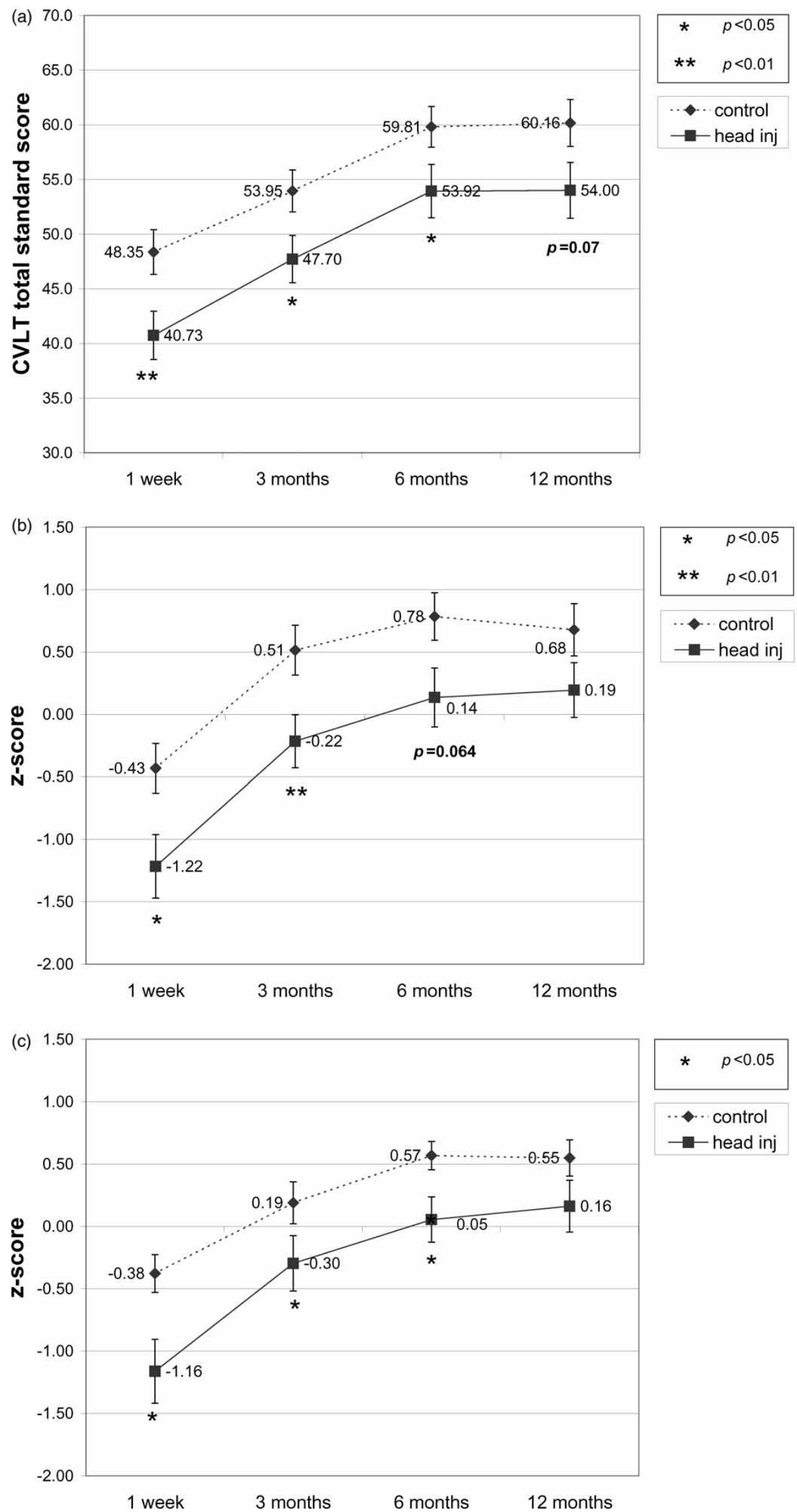

Figure 7. California Verbal Learning Test: CVLT total standard score (a), short delay free recall (b) and short delay cued recall (c). Error bars show standard errors. 

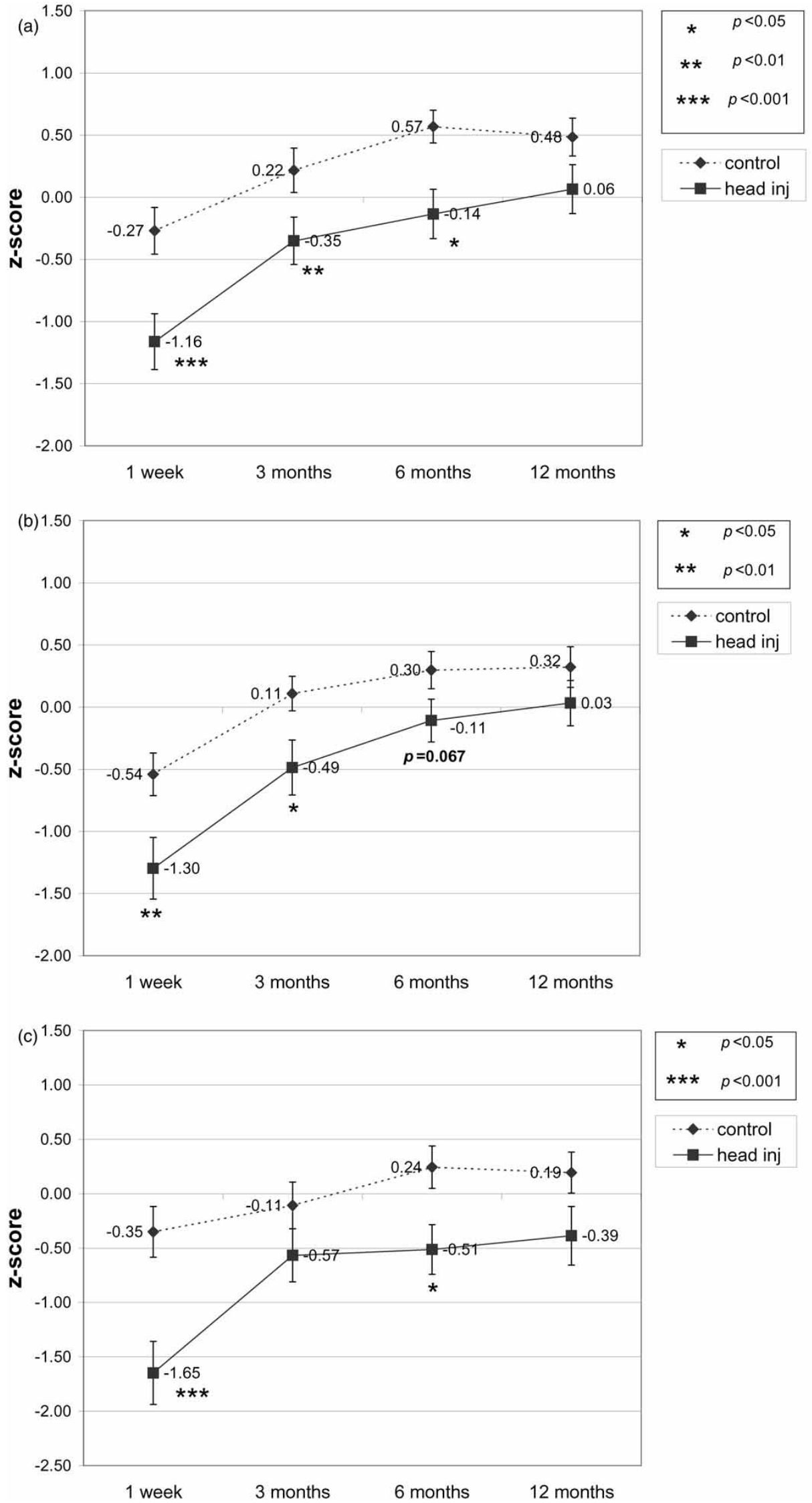

Figure 8. California Verbal Learning Test: Long delay free recall (a), long-delay cued recall (b) and CVLT List A/trial 5 (c). Error bars show standard errors. 
Table I. Recovery throughout the first year.

\begin{tabular}{lcccc}
\hline Rivermead Post-concussion Symptoms Questionnaire & 1 week & 3 months & 6 months & 12 months \\
\hline (a) Patients who are entirely symptom-free (\%) & 0.0 & 16.2 & 13.5 \\
(b) Patients without injury-related increase in RPSQ symptom levels (\%) $)^{\star \star}$ & 8.1 & 40.5 & 48.6 & 48.7 \\
\hline
\end{tabular}

${ }^{\star}$ This is a sub-group of group B. ${ }^{\star \star}$ No scores of 2 or higher on any symptoms (i.e. no symptom is more pronounced than pre-injury).

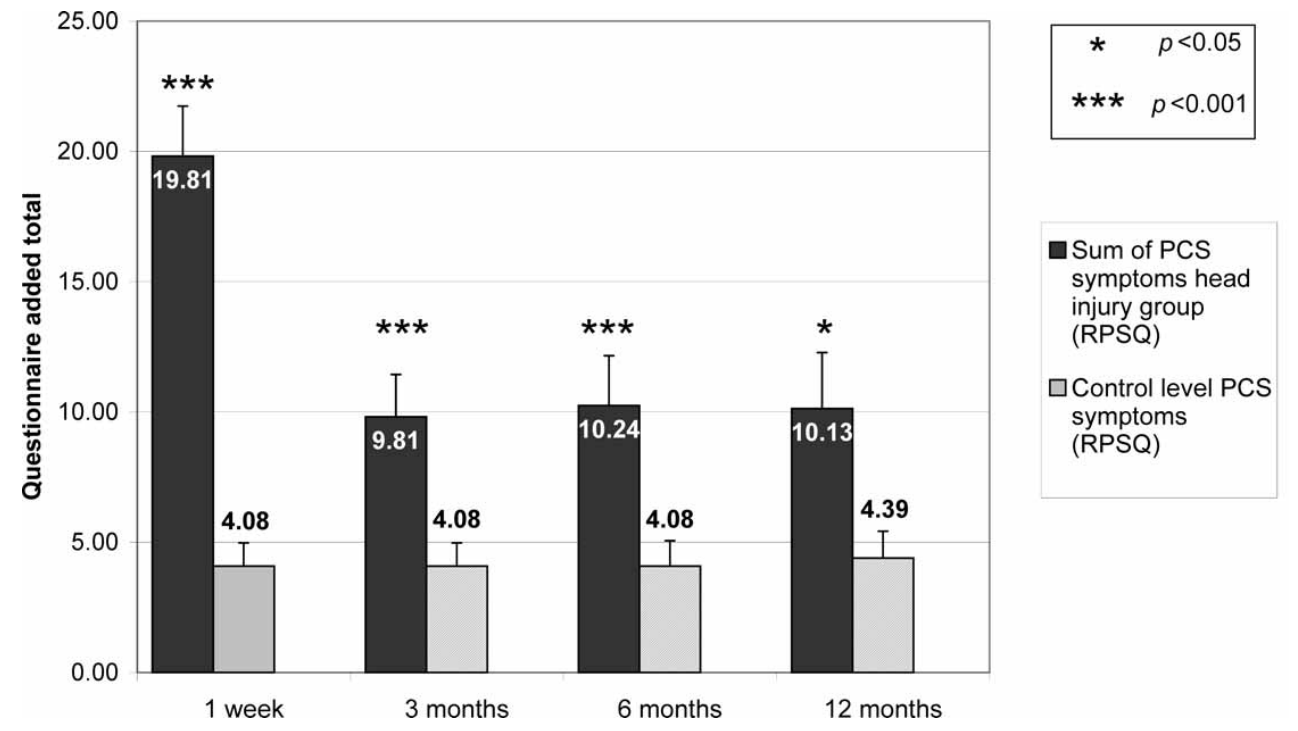

Figure 9. Mean total scores on the Rivermead Post-concussion Symptoms Questionnaire (RPSQ) throughout 1 year post-injury. Error bars show standard errors.

deficits on several motor tasks including antisaccades, memory-guided sequences, fast sinusoidal smooth pursuit, upper-limb step, sine and random tracking as well as ballistic upper-limb movement peak velocity. Coupled with previous work [31-33], this finding indicates a consistent and reproducible impact of mild head trauma on eye and arm motor control.

The finding of motor impairment persisting beyond 1 week of mild head trauma suggests an unexpectedly profound adverse impact of mild head trauma on eye and arm motor control and the cerebral components mediating motor function. The profile of motor deficits at 1 week conveyed a picture of multi-focal dysfunction very similar to that discussed previously [31-33] and consistent with cerebral abnormalities seen in imaging studies after mild CHI [7, 9-12, 59]. The composition of eye and upper-limb motor deficits persisting beyond 1 week is consistent with a prolonged impairment of motor functions originating in frontal cortical areas (i.e. supplementary motor area, primary and pre-motor cortex), posterior parietal cortex and hippocampal formation, areas shown by functional imaging to be adversely affected at 3 and more months after mild CHI [9-12, 59, 60].
The deficits in motor function gradually improved during the first year post-injury, reflecting an ongoing recovery process, parallel to the improved symptom profile. Even though a small performance improvement on some measures was also apparent in the controls-this indicating the influence of practice effects-the group with CHI performed consistently worse than the controls with statistically significant deficits persisting up to 6 and, in the case of upper-limb step tracking and fast sinusoidal smooth pursuit, 12 months post-injury.

It might be argued that these motor impairments could equally have been caused by cognitive deficits, in particular factors related to attention, rather than disturbances in motor processing due to a physical impact of head trauma on the networks for motor control. However, any relevant impairment of cognitive/attentional factors should have manifested in statistically significant group differences on the PASAT, SDMT, TMT (especially time-to-completion and errors on the TMT B [61]) and the CVLT attention-span factor derived from first recall of List A and List B [62]. Preserved performance on the PASAT and TMT suggests preservation of cognitive functions such as sustained and divided attention, information 
processing capacity, short-term and working memory [41, 63-67]. The group with CHI showed transient deficits on the SDMT at 1 week, which suggests impaired speed of information processing at this point in time [55], but the SDMT abnormalities had recovered by 3 months. The absence of any statistically significant deficits beyond 1 week on the PASAT, SDMT and TMT, in combination with the preserved performance on the WASI, indicates largely normal levels of cognitive functioning, good levels of attention, working memory and speed of information processing in the patient group and supports the conclusion that the impaired motor performance was not caused by deficits in these functions.

The inability of neuropsychological testing, with exception of the CVLT, to document a recovery profile emphasizes the notion that motor testing may provide a sensitive and useful marker of residual brain dysfunction, particularly in patients who present with persistent post-concussional symptoms or complaints months after their injury. In contrast to the concomitant occurrence of neuropsychological impairment (i.e. on tests such as PASAT, SDMT and TMT) and oculomotor deficits (i.e. reflexive, anti- and memory-guided saccades) after severe head injury [41], the findings indicate that deficits in motor function are still apparent after mild CHI, whilst cerebral dysfunction, with the exception of deficits on verbal learning/declarative verbal memory, may not necessarily manifest in detectable neuropsychological deficits beyond 1 month of mild CHI. These observations are consistent with previous evidence that mild $\mathrm{CHI}$ is unlikely to reliably produce persisting psychometric abnormalities [24, 68-71]. In addition, the likelihood of abnormal neuropsychological performance indicating the presence of a pathological condition is low following mild head trauma [27] due to the susceptibility of neuropsychological testing to pre-morbid intelligence and other factors such as age, level of education, state of employment and socioeconomic status [24-26]. The current and previous [32] observations support the conclusion that instrumented motor testing is unaffected by these factors and can indicate the presence of ongoing dysfunction at a level not easily accessible with conventional neuropsychological assessment after mild CHI.

\section{Limitations of the current study}

Whilst this study uncovered the presence of persistent eye and upper-limb visuomotor deficits after mild CHI, it has to be acknowledged that the level of impairment was subtle and that any useful application of motor testing in a clinical context after mild
CHI should not be based on the assessment of a few isolated motor measures. The current findings imply that it is unlikely that there are 'master-measures' (i.e. single measures of motor function that can be a sole indicator of pathology in individuals). The step of an useful transformation of the current (grouplevel) motor deficits into an application with utility for individual patients suffering from mild CHI can only be achieved by way of regression-based modelling, ideally using larger groups. Such models should be able to channel the effect detected in the current study into a format that allows the discrimination between normal and abnormal motor performance on an individual level and thereby open a pathway for the potential use of motor ability as a marker of functional impairment in the absence of gross movement deficits. Preliminary work on this issue suggests that such models will likely include several key measures that manifest deficits at a sample size of $n=37$ in addition to other variables with weaker performance gradients that do not show significant deficits in small samples but still contribute in a useful manner to identifying patients with abnormalities in brain function after mild CHI. There are also indications that such modelling may allow the very efficient use of early motor assessment to predict adverse outcome during the first 6 months after mild head trauma [72].

\section{Conclusion}

The results suggest that motor assessment as employed in the present study may provide a new and objective way of screening for the presence of residual brain dysfunction in the months following mild head trauma. This study has shown that unsuspected eye and arm motor deficits can persist for several months post-injury using techniques which can objectively detect and measure such deficits. The susceptibility of eye and arm motor function to deficits throughout the first year following mild CHI suggests that the instrumented assessment of motor function may be useful in providing sensitive and objective markers of cerebral dysfunction. Such independent markers may be of value in confirming injury status and ongoing cerebral dysfunction in patients who present with reports of persistent post-concussional symptoms and complaints in the months post-injury.

\section{Acknowledgements}

The study was hosted by the Canterbury District Health Board and the Christchurch School of 
Medicine \& Health Sciences, University of Otago, New Zealand. Funding for patients' travel costs was provided by the Neurological Foundation of New Zealand (NFNZ grant number 0027/SPG). We would like to thank these institutions for their support of this research.

\section{References}

1. Jennett B. Epidemiology of head injury. Journal of Neurology, Neurosurgery and Psychiatry 1996;60:362-369.

2. Kraus JF, Nourjah P. The epidemiology of mild head injury. In: Levin HS, Eisenberg HM, Benton AL, editors. Mild head injury. New York: Oxford University Press; 1989. pp 8-22.

3. Jager TE, Weiss HB, Coben JH, Pepe PE. Traumatic brain injuries evaluated in U.S. emergency departments, 1992-1994. Academic Emergency Medicine 2000;7: 134-140.

4. Max W, MacKenzie EJ, Rice DP. Head injuries: Costs and consequences. Journal of Head Trauma Rehabilitation 1991;6:76-91.

5. Kraus JF, Nourjah P. The epidemiology of mild uncomplicated brain injury. Journal of Trauma 1988;28: 1637-1643.

6. McGregor K, Pentland B. Head injury rehabilitation in the U.K.: An economic perspective. Social Science and Medicine 1997;45:295-303.

7. McAllister TW, Sparling MB, Flashman LA, Saykin AJ. Neuroimaging findings in mild traumatic brain injury. Journal of Clinical and Experimental Neuropsychology 2001;23:775-791.

8. Blumbergs PC, Scott G, Manavis J, Wainwright $\mathrm{H}$, Simpson DA, McLean AJ. Staining of amyloid precursor protein to study axonal damage in mild head injury. Lancet 1994;344:1055-1056.

9. Hofman PA, Verhey FR, Wilmink JT, Rozendaal N, Jolles J. Brain lesions in patients visiting a memory clinic with postconcussional sequelae after mild to moderate brain injury. Journal of Neuropsychiatry and Clinical Neurosciences 2002;14:176-184.

10. Kant R, Smith-Seemiller L, Isaac G, Duffy J. Tc-HMPAO SPECT in persistent post-concussion syndrome after mild head injury: Comparison with MRI/CT. Brain Injury 1997;11:115-124.

11. Abu-Judeh HH, Parker R, Singh M, el-Zeftawy H, Atay S, Kumar M, Naddaf S, Aleksic S, Abdel-Dayim HM. SPET brain perfusion imaging in mild traumatic brain injury without loss of consciousness and normal computed tomography. Nuclear Medicine Communications 1999;20: 505-510.

12. Jacobs A, Put E, Ingels $M$, Put $T$, Bossuyt A. One-year follow-up of technetium-99m-HMPAO SPECT in mild head injury. Journal of Nuclear Medicine 1996;37:1605-1609.

13. McAllister TW, Sparling MB, Flashman LA, Guerin SJ, Mamourian AC, Saykin AJ. Differential working memory load effects after mild traumatic brain injury. Neuroimage 2001;14:1004-1012.

14. Ommaya AK. Head injury mechanisms and the concept of preventive management: A review and critical synthesis. Journal of Neurotrauma 1995;12:527-546.

15. Centers for Disease Control and Prevention, National Center for Injury Prevention and Control. Traumatic brain injury in the United States-A report to Congress. Atlanta, GA: Centers for Disease Control and Prevention; 1999.
16. Wrightson P, Gronwall D. Mild head injury in New Zealand: Incidence of injury and persisting symptoms. New Zealand Medical Journal 1998;111:99-101.

17. Mallinson AI, Longridge NS. Specific vocalized complaints in whiplash and minor head injury patients. American Journal of Otology 1998;19:809-813.

18. Bohnen N, Jolles J. Neurobehavioral aspects of postconcussive symptoms after mild head injury. Journal of Nervous and Mental Disease 1992;180:683-692.

19. Mittenberg W, Canyock EM, Condit D, Patton D. Treatment of post-concussion syndrome following mild head injury. Journal of Clinical and Experimental Neuropsychology 2001;23:829-836.

20. Bazarian JJ, Wong T, Harris M, Leahey N, Mookerjee S, Dombovy M. Epidemiology and predictors of post-concussive syndrome after minor head injury in an emergency population. Brain Injury 1999;13:173-189.

21. Levin HS, Williams DH, Eisenberg HM, High WM, Jr, Guinto FC, Jr. Serial MRI and neurobehavioural findings after mild to moderate closed head injury. Journal of Neurology, Neurosurgery and Psychiatry 1992;55:255-262.

22. Umile EM, Plotkin RC, Sandel ME. Functional assessment of mild traumatic brain injury using SPECT and neuropsychological testing. Brain Injury 1998;12:577-594.

23. Radanov BP, Bicik I, Dvorak J, Antinnes J, von Schulthes GK, Buck A. Relation between neuropsychological and neuroimaging findings in patients with late whiplash syndrome. Journal of Neurology, Neurosurgery and Psychiatry 1999;66:485-489.

24. Ponsford J, Willmott C, Rothwell A, Cameron P, Kelly AM, Nelms R, Curan C, Ng K. Factors influencing outcome following mild traumatic brain injury in adults. Journal of the International Neuropsychological Society 2000;6:568-579.

25. Dikmen S, Machamer J, Temkin N. Mild head injury: Facts and artifacts. Journal of Clinical and Experimental Neuropsychology 2001;23:729-738.

26. Reitan RM, Wolfson D. The significance of sensory-motor functions as indicators of brain dysfunction in children. Archives of Clinical Neuropsychology 2003;18:11-18.

27. Binder LM, Rohling ML, Larrabee J. A review of mild head trauma. Part I: Meta-analytic review of neuropsychological studies. Journal of Clinical and Experimental Neuropsychology 1997;19:421-431.

28. De Kruijk JR, Leffers P, Menheere PPCA, Meerhoff S, Rutten J, Twijnstra A. Prediction of post-traumatic complaints after mild traumatic brain injury: early symptoms and biochemical markers. Journal of Neurology, Neurosurgery and Psychiatry 2002;73:727-732.

29. Savola O, Hillbom M. Early predictors of post-concussion symptoms in patients with mild head injury. European Journal of Neurology 2003;10:175-181.

30. Ingebrigtsen $\mathrm{T}$, Waterloo $\mathrm{K}$, Jacobsen $\mathrm{EA}$, Langbakk $\mathrm{B}$, Romner B. Traumatic brain damage in minor head injury: Relation of serum S-100 protein measurements to magnetic resonance imaging and neurobehavioral outcome. Neurosurgery 1999;45:468-475; discussion 475-476.

31. Heitger MH, Anderson TJ, Jones RD. Saccade sequences as markers for cerebral dysfunction following mild closed head injury. Progress in Brain Research 2002; 140:433-448.

32. Heitger MH, Anderson TJ, Jones RD, et al. Eye movement and visuomotor arm movement deficits following mild closed head injury. Brain 2004;127:575-590.

33. Heitger $\mathrm{MH}$, MacAskill MR, Jones RD, DalrympleAlford JC, Frampton CM, Ardagh MW. The impact of mild closed head injury on involuntary saccadic adaptation - evidence for the preservation of implicit motor learning. Brain Injury 2005;19:109-117. 
34. Pierrot-Deseilligny C, Muri RM, Ploner CJ, et al. Cortical control of ocular saccades in humans: A model for motricity. Progress in Brain Research 2003;142:3-17.

35. Jones RD. Measurement of sensory-motor control performance capacities: Tracking tasks. In: Bronzino JD, editor. The biomedical engineering handbook. 2nd ed. Boca Raton (FL): CRC Press; 2000. pp 1-25.

36. Sweeney JA, Mintun MA, Kwee S, Wiseman MB, Brown DL, Rosenberg DR, Carl JR. Positron emission tomography study of voluntary saccadic eye movements and spatial working memory. Journal of Neurophysiology 1996;75:454-468.

37. Anderson TJ, Jenkins IH, Brooks DJ, Hawken MB, Franckowian RS. Cortical control of saccades and fixation in man. A PET study. Brain 1994;117:1073-1084.

38. Hamzei F, Dettmers C, Rijntjes M, Glauche V, Kiebei S, Weber B, Weiller C. Visuomotor control within a distributed parieto-frontal network. Experimental Brain Research 2002;146:273-281.

39. Ellermann JM, Siegal JD, Strupp JP, Ebner TJ, Ugurbil K. Activation of visuomotor systems during visually guided movements: A functional MRI study. Journal of Magnetic Resonance 1998;131:272-285.

40. Graziano MS, Taylor CS, Moore T, Cooke DF. The cortical control of movement revisited. Neuron 2002;36:349-362.

41. Williams IM, Ponsford JL, Gibson KL, Mulhall LE, Curran CA, Abel LA. Cerebral control of saccades and neuropsychological test results after head injury. Journal of Clinical Neuroscience 1997;4:186-196.

42. Haaland KY, Temkin N, Randahl G, Dikmen S. Recovery of simple motor skills after head injury. Journal of Clinical and Experimental Neuropsychology 1994;16:448-456.

43. Hills EC, Geldmacher DS. The effect of character and array type on visual spatial search quality following traumatic brain injury. Brain Injury 1998;12:69-76.

44. Prigatano GP. Impaired awareness, finger tapping, and rehabilitation outcome after brain injury. Rehabilitation Psychology 1999;44:145-159.

45. Perbal S, Couillet J, Azouvi P, Pouthas V. Relationships between time estimation, memory, attention, and processing speed in patients with severe traumatic brain injury. Neuropsychologia 2003;41:1599-1610.

46. Jones RD, Donaldson IM. Measurement of integrated sensory-motor function following brain damage by a computerized preview tracking task. International Rehabilitation Medicine 1981;3:71-83.

47. Haggard P, Miall RC, Wade D, Fowler S, Richardson A, Anslow P, Stein J. Damage to cerebellocortical pathways after closed head injury: A behavioural and magnetic resonance imaging study. Journal of Neurology, Neurosurgery and Psychiatry 1995;58:433-438.

48. Sietsema JM, Nelson DL, Mulder RM, Mervau-Scheidel D, White BE. The use of a game to promote arm reach in persons with traumatic brain injury. American Journal of Occupational Therapy. 1993;47:19-24.

49. Swaine BR, Sullivan SJ. Relation between clinical and instrumented measures of motor coordination in traumatically brain injured persons. Archives of Physical Medicine \& Rehabilitation 1992;73:55-59.

50. Kuhtz-Buschbeck JP, Stolze H, Golge M, Ritz A. Analyses of gait, reaching, and grasping in children after traumatic brain injury. Archives of Physical Medicine \& Rehabilitation 2003;84:424-430.

51. Reulen JPH, Marcus JT, Koops D, de Vries FR, Tiesinga G, Boshuizen K, Bos JE. Precise recording of eye movement: The IRIS technique Part 1. Medical and Biological Engineering and Computing 1988;26:20-26.
52. Muir SR, MacAskill MR, Herron D, et al. EMMA—an eye movement measurement and analysis system. Australasian Physical and Engineering Sciences in Medicine 2003;26:18-24.

53. Gronwall DMA. Paced auditory serial addition test (PASAT). Victoria, Canada: Department of Psychology, University of Victoria; 1977.

54. Delis DC, Kramer JH, Kaplan E, Ober BA. California verbal learning test (CVLT). San Antonio: The Psychological Corporation ${ }^{\circledR}$, Harcourt Brace \& Company; 1987.

55. Smith A. Symbol digit modalities test. Los Angeles, CA: Western Psychological Services; 1973.

56. Spreen O, Strauss E. A compendium of neuropsychological tests. New York: Oxford University Press; 1991.

57. The Psychological Corporation. Wechsler abbreviated scale of intelligence-manual. San Antonio: The Psychological Corporation; 1999.

58. King NS, Crawford S, Wenden FJ, Moss NE, Wade DT. The Rivermead Post Concussion Symptoms Questionnaire: A measure of symptoms commonly experienced after head injury and its reliability. Journal of Neurology $1995 ; 242: 587-592$.

59. Chen SH, Kareken DA, Fastenau PS, Trexler LE, Hutchins GD. A study of persistent post-concussion symptoms in mild head trauma using positron emission tomography. Journal of Neurology, Neurosurgery and Psychiatry 2003;74:326-332.

60. Gray BG, Ichise M, Chung DG, Kirsch JC, Franks W. Technetium-99m-HMPAO SPECT in the evaluation of patients with a remote history of traumatic brain injury: A comparison with x-ray computed tomography. Journal of Nuclear Medicine 1992;33:52-58.

61. Ruffolo LF, Guilmette TJ, Willis GW. Comparison of time and error rates on the trail making test among patients with head injuries, experimental malingerers, patients with suspect effort on testing, and normal controls. Clinical Neuropsychologist 2000;14:223-230.

62. Wiegner S, Donders J. Performance on the California Verbal Learning Test after traumatic brain injury. Journal of Clinical and Experimental Neuropsychology 1999;21:159-170.

63. Gronwall D. Cumulative and persisting effects of concussion on attention and cognition. In: Levin HS, Eisenberg HM, Benton AL, editors. Mild head injury. New York: Oxford University Press; 1989. pp 153-162.

64. Sherman EMS, Strauss E, Spellacy F. Validity of the Paced Auditory Serial Addition Test (PASAT) in adults referred for neuropsychological assessment after head injury. Clinical Neuropsychologist 1997;11:34-45.

65. Anderson CV, Bigler ED, Blatter DD. Frontal lobe lesions, diffuse damage, and neuropsychological functioning in traumatic brain-injured patients. Journal of Clinical and Experimental Neuropsychology 1995;17: 900-908.

66. Arbuthnott K, Frank J. Trail making test, part B as a measure of executive control: Validation using a set-switching paradigm. Journal of Clinical and Experimental Neuropsychology 2000;22:518-528.

67. Di Stefano G, Radanov BP. Course of attention and memory after common whiplash: A two-years prospective study with age, education and gender pair-matched patients. Acta Neurologica Scandinavica 1995;91:346-352.

68. Dikmen S, McLean A, Temkin N. Neuropsychological and psychosocial consequences of minor head injury. Journal of Neurology, Neurosurgery and Psychiatry 1986;49:1227-1232.

69. Levin HS, Mattis S, Ruff RM, Eisenberg HM, Marshall LF, Tabaddor K, High WM, Jr, 
Frankowski RF. Neurobehavioral outcome following minor head injury: A three-center study. Journal of Neurosurgery 1987;66:234-243.

70. Gentilini M, Nichelli P, Schoenhuber R, et al. Neuropsychological evaluation of mild head injury. Journal of Neurology, Neurosurgery and Psychiatry 1985;48:137-140.
71. Richardson JTE. Clinical and neuropsychological aspects of closed head injury. Brain damage, behaviour and cognition series. Hove (UK): Psychology Press; 2000.

72. Heitger MH, Anderson TJ, Jones RD. A role for instrumented motor assessment in clinical assessment and outcome prediction after mild head injury (Abstract). Brain Injury 2005;19(Suppl 1):111. 